OPEN ACCESS

Edited by:

Ino Curik,

University of Zagreb, Croatia

Reviewed by: Ikhide G. Imumorin Cornell University, USA Martino Cassandro, University of Padova, Italy

*Correspondence:

Sandrine I. Duchemin sandrine.duchemin@slu.se

Specialty section:

This article was submitted to Livestock Genomics,

a section of the journal

Frontiers in Genetics

Received: 17 November 2015 Accepted: 25 March 2016

Published: 15 April 2016

Citation:

Duchemin SI, Glantz M, de Koning D-J, Paulsson M and Fikse WF

(2016) Identification of QTL on

Chromosome 18 Associated with Non-Coagulating Milk in Swedish Red

Cows. Front. Genet. 7:57.

doi: 10.3389/fgene.2016.00057

\section{Identification of QTL on Chromosome 18 Associated with Non-Coagulating Milk in Swedish Red Cows}

\author{
Sandrine I. Duchemin ${ }^{1,2 *}$, Maria Glantz ${ }^{3}$, Dirk-Jan de Koning ${ }^{1}$, Marie Paulsson ${ }^{3}$ and \\ Willem F. Fikse ${ }^{1}$ \\ ${ }^{1}$ Department of Animal Breeding and Genetics, Swedish University of Agricultural Sciences, Uppsala, Sweden, ${ }^{2}$ Animal \\ Breeding and Genomics Centre, Wageningen University, Wageningen, Netherlands, ${ }^{3}$ Department of Food Technology, \\ Engineering and Nutrition, Lund University, Lund, Sweden
}

Non-coagulating (NC) milk, defined as milk not coagulating within 40 min after rennet-addition, can have a negative influence on cheese production. Its prevalence is estimated at $18 \%$ in the Swedish Red (SR) cow population. Our study aimed at identifying genomic regions and causal variants associated with NC milk in SR cows, by doing a GWAS using 777k SNP genotypes and using imputed sequences to fine map the most promising genomic region. Phenotypes were available from 382 SR cows belonging to 21 herds in the south of Sweden, from which individual morning milk was sampled. NC milk was treated as a binary trait, receiving a score of one in case of non-coagulation within 40 min. For all 382 SR cows, 777k SNP genotypes were available as well as the combined genotypes of the genetic variants of $\alpha s 1-\beta$ - $\kappa$-caseins. In addition, whole-genome sequences from the 1000 Bull Genome Consortium (Run 3) were available for 429 animals of 15 different breeds. From these sequences, 33 sequences belonged to SR and Finish Ayrshire bulls with a large impact in the SR cow population. Single-marker analyses were run in ASReml using an animal model. After fitting the casein loci, 14 associations at $-\log _{10}(P$-value $)>6$ identified a promising region located on BTA18. We imputed sequences to the 382 genotyped SR cows using Beagle 4 for half of BTA18, and ran a region-wide association study with imputed sequences. In a seven mega base-pairs region on BTA18, our strongest association with NC milk explained almost $34 \%$ of the genetic variation in NC milk. Since it is possible that multiple QTL are in strong LD in this region, 59 haplotypes were built, genetically differentiated by means of a phylogenetic tree, and tested in phenotype-genotype association studies. Haplotype analyses support the existence of one QTL underlying NC milk in SR cows. A candidate gene of interest is the VPS35 gene, for which one of our strongest association is an intron SNP in this gene. The VPS35 gene belongs to the mammary gene sets of pre-parturient and of lactating cows.

Keywords: non-coagulating milk, sequences, dairy, cheese production, haplotypes, VPS35 


\section{INTRODUCTION}

Non- or poor-coagulating milk is an undesirable characteristic of milk with a negative influence on cheese production. Noncoagulating (NC) milk is prevalent among several dairy cattle breeds, such as Swedish Red (SR), Finnish Ayrshire (FAY), Holstein-Friesian (HF) and Italian Brown Swiss, to name a few (e.g., Cecchinato et al., 2011; Frederiksen et al., 2011; Gustavsson et al., 2014a). The prevalence of NC milk varies among these breeds ranging from $4 \%$ in Italian Brown Swiss (Cecchinato et al., 2009) up to $13 \%$ in FAY (Ikonen et al., 2004). A recent study has estimated the prevalence of NC milk, defined as milk not coagulating within $40 \mathrm{~min}$ after rennet-addition, at $18 \%$ in the SR cow population (Gustavsson et al., 2014a). Targeted research on NC milk can help geneticists develop breeding programs to modify milk composition and technological properties of milk and thus reduce the prevalence of NC milk.

Bittante et al. (2012) suggested that effects of herd have little influence on milk coagulation properties (MCP) including NC milk, although several factors can influence the composition of bovine milk (e.g., breed, a cow's diet, age of a cow, and the stage of lactation; Chilliard et al., 2001). In addition, MCP seem to be influenced by many factors, such as SCC (e.g., Ikonen et al., 2004; Cassandro et al., 2008), titratable acidity (e.g., Penasa et al., 2010), casein composition (Okigbo et al., 1985b), pH (Nájera et al., 2003), stage of lactation (Okigbo et al., 1985a; Ostersen et al., 1997), and breed (e.g., Auldist et al., 2004; De Marchi et al., 2007; Bittante et al., 2012), among many other factors. Heritability estimates for MCP and NC milk range from 0.26 in FAY (Ikonen et al., 2004) to 0.45 in SR cows (Gustavsson et al., 2014a). These heritability estimates suggest that breeding could effectively reduce the prevalence of NC milk. In Sweden, the breeding program includes production traits to guarantee the increase in both protein and fat contents (Nordic Cattle Genetic Evaluation, 2013). The negative genetic correlations between NC milk and protein content estimated by Gustavsson et al. (2014a) suggest that breeding for higher protein content in the SR cows can lead to an increase in the prevalence of NC milk. In Sweden, $41 \%$ of SR cows produce milk for the dairy industry, and more than $30 \%$ of total milk production is used for cheese production (LRF Dairy Sweden, 2015). Since, total milk production is about 3 million tons per year (LRF Dairy Sweden, 2015) and the market price of milk produced is about 0.28 euros per $\mathrm{kg}$, the problem of NC milk affects milk with a value of $\sim 63$ million euros per year. Frederiksen et al. (2011) has estimated in $25 \%$ the proportion of NC milk in a batch of well-coagulating milk that is sufficient to deteriorate the MCP of well-coagulating milk. Van Hooydonk et al. (1986) showed that the addition of calcium would restore

Abbreviations: AR2, beagle's accuracy of imputation; BovineHD, 777,963 SNP genotypes; BTA, Bos taurus autosome; CN, caseins; CTrennet, rennet coagulation time; FAY, Finnish Ayrshire; G'30, rennet gel strength measured $30 \mathrm{~min}$ after chymosin addition; GWAS, genome-wide association study; LD, linkage disequilibrium; MAF, minor allele frequency; MBP, mega base-pair; MCP, milk coagulation properties; NC, non-coagulating; QTL, quantitative trait loci; RWAS, region-wide association study; SR, Swedish Red; TagSNP1, most significant association retrieved from RWAS; Ve!P, variant effect predictor; WGS, wholegenome sequences. coagulation of NC milk but not to the level of well-coagulating milk according to Hallén et al. (2010). Furthermore, addition of calcium above $0.04 \%$ have been reported to produce a bitter flavor (Schwarz and Mumm, 1948) which could be detrimental to cheese production. Therefore, it is important to the Swedish industry to reduce the frequency of NC milk.

It is well-established that MCP, including NC milk, are strongly influenced by variable proportions, and genetic variants of milk protein fractions [especially of $\kappa$-casein $(\mathbf{C N})$; (Bittante et al., 2012)]. In poor- and non-coagulating milk samples of Danish Jerseys and HF cows, Jensen et al. (2012) showed that $\mathrm{BB}-\mathrm{A}^{2} \mathrm{~A}^{2}$-AA was the predominant combined genotype of $\alpha_{\mathrm{S1}^{-}}$, $\beta$-, and $\kappa-\mathrm{CN}$ associated with NC milk. Hallén et al. (2007) and Gustavsson et al. (2014b) showed that some of these genotypes (especially $\beta$-, and $\kappa-\mathrm{CN}$ genotypes $\mathrm{A}^{2} \mathrm{~A}^{2}-\mathrm{AA}$ ) segregate in $\mathrm{SR}$ cows. Besides these genetic variants of milk protein fractions in the cattle genome, other undiscovered genes might play a role in the prevalence of NC milk. These genes can be identified by genome-wide association studies (GWAS) using high-density genotyping techniques.

High-density genotyping techniques, such as whole-genome sequences (WGS), can help GWAS increase the power and the precision of quantitative trait loci $(\mathbf{Q T L})$ mapping. WGS are expected to contain most of the polymorphisms causing the genetic differences between individuals (Meuwissen and Goddard, 2010). When an entire population is sequenced, WGS are independent of linkage disequilibrium (LD) between polymorphisms and the causal variant (Druet et al., 2014) in comparison with a lower panel of markers. However, sequencing an entire population can be expensive, and a costeffective strategy consists of sequencing key ancestors of a population, and imputing to sequence level the rest of this population (Druet et al., 2014). To demonstrate this approach, Daetwyler et al. (2014) imputed dairy cattle populations that were genotyped with 777k SNP (BovineHD) to sequence level using WGS from the 1000 Bull Genome Consortium. Their study targeted some known genomic regions where QTL affecting milk production and curly coat had previously been identified, and they successfully identified the causal variants underlying these QTL. Therefore, GWAS using imputed sequences could assist in the identification of causal variants.

A recent GWAS in SR cows used BovineHD as genotypes and MCP as phenotypes (Gregersen et al., 2015). However, their GWAS did not include NC milk in the analyses. The aim of our study was to identify genomic regions and causal variants associated with NC milk in SR cows. For this purpose, firstly we ran a GWAS using BovineHD genotypes to identify the most promising genomic region associated with NC milk, and secondly we fine-mapped this genomic region using imputed sequences.

\section{MATERIALS AND METHODS}

\section{Animals and Phenotypes}

Morning milk samples were retrieved from 382 SR cows belonging to 21 herds in the southern part of Sweden. Cows were kept indoors, were fed according to standard practices, and were 
milked 2 or 3 times a day. Cows were daughters of 160 sires, and were chosen to be as genetically unrelated as possible. Cows were multiparous, ranging from 1 through 3 parturitions, and were in different lactations stages, ranging from 2.5 through 61 weeks in lactation.

Milk samples were collected in two distinct periods: April through May 2010, and September 2010 through April 2011. Directly after collection, milk samples were cooled and transported to Lund University (Lund, Sweden), where samples were defatted by centrifugation (at $2000 \times \mathrm{g}$ for $30 \mathrm{~min}$ ) to reduce the number of factors influencing coagulation properties. Fresh skimmed milk samples were preserved by adding bronopol (Sigma-Aldrich, Schnelldorf, Germany) solution of $17 \% \mathrm{wt} / \mathrm{vol}$ $(2 \mu \mathrm{L} / \mathrm{mL})$, as described in Hallén et al. (2007). For rheological measurements, these milk samples were stored at $+4^{\circ} \mathrm{C}$, but no longer than 3 days. Skimmed milk samples were heated to $32^{\circ} \mathrm{C}$ for $30 \mathrm{~min}$, after which chymosin $(0.44 \mathrm{~mL} / \mathrm{L}$ Chy-Max Plus, 205 international milk clotting units (IMCU)/mL, Chr. Hansen A/S Hørsholm, Denmark) was added, and the resulting solution was gently stirred. The addition of the chymosin represented time zero. Measurements, such as rennet gel strength, rennet coagulation time, and yield stress of rennet-induced gels, were done and described by Gustavsson et al. (2014a). Some samples were unable to coagulate within $40 \mathrm{~min}$ after rennet-addition, and were defined as NC milk samples. When observed, NC milk was scored as one, while coagulating milk was scored as zero. Of the 382 cows that had available phenotypes on coagulation properties, $18 \%$ of these cows had NC milk.

\section{Genotypes}

A blood sample of each of the 382 SR cows was collected for genotyping purposes. These cows were genotyped for 777,963 SNP using the Illumina BovineHD BeadChip (Illumina Inc., San Diego, CA). Quality controls of the data were performed using the R-package GenAbel (Aulchenko et al., 2007), and consisted of a minimum of $95 \%$ of non-missing SNP per called genotypes (call rate) and minor allele frequency (MAF) of a minimum of $1 \%$ for a called SNP. All SNP without a map position on the UMD 3.1 genome assembly (Zimin et al., 2009) as well as SNP on the sex chromosome were discarded. After these edits, a total of 624,302 SNP were available for further analyses.

In addition, blood samples were used to extract DNA to genotype all cows for the genetic variants of $\alpha$ s1-, $\beta$ - and $\kappa$ caseins $(\mathbf{C N})$ using TaqMan SNP genotyping assays (Applied Biosystems, Foster City, CA), as described in Gustavsson et al. (2014b). For these variants, the assays were distinguished among the following: $\alpha s 1-\mathrm{CN}$ variant $\mathrm{A}, \mathrm{B}, \mathrm{C}, \mathrm{D}$, and $\mathrm{F} ; \beta-\mathrm{CN}$ variants $\mathrm{A}^{1}, \mathrm{~A}^{2}, \mathrm{~A}^{3}, \mathrm{~B}$, and $\mathrm{I}$; and $\kappa-\mathrm{CN}$ variants $\mathrm{A}, \mathrm{B}$, and $\mathrm{E}$. In their study, combined genotypes were created by combining the genetic variants of $\alpha s 1-\beta-\kappa-C N$. These combined genotypes were used in the present study, and are referred to as "CNcluster."

Whole-genome sequences were available for 428 bulls and for one cow from 15 different breeds (Run three of the 1000 Bull Genomes consortium; Daetwyler et al., 2014), representing a multi-breed reference population. Among these sequences, 33 belonged to SR and FAY bulls with a large impact in the SR cow population. All positions of the variants on sequences were aligned to the bovine genome assembly UMD3.1 (Zimin et al., 2009). Within this multi-breed reference population, positions containing both a SNP and an indel were excluded because of possible problems with alignment and sequencing.

\section{GWAS on BovineHD Genotypes}

Single-marker analyses were run in ASReml 4.0 (Beta version; Gilmour et al., 2009) using the following animal model:

$$
\begin{aligned}
y= & \mu+\text { herd }+ \text { parity }+ \text { wim }+e^{-0.05 * \text { wim }}+\text { CNcluster } \\
& + \text { Marker }+a+e
\end{aligned}
$$

where $y$ is the dependent variable; $\mu$ is the overall mean, herd is the covariate that describes the effect of a cow belonging to a specific herd; parity is the covariate that describes the effect of number of parities per cow; wim is the covariate that describes the effect of weeks in milk, modeled as a Wilmink curve (Wilmink, 1987); CNcluster is the covariate describing the effect of the combined genotypes; Marker is the fixed effect of a variant genotype; $a$ is the random effect of animal and is assumed to be distributed as $N \sim\left(0, \boldsymbol{G} \sigma_{a}^{2}\right)$, where $\boldsymbol{G}$ is the genomic relationship matrix based on 382 animals and $\sigma_{a}^{2}$ is the additive genetic variance. We calculated the G-matrix based on the BovineHD genotypes using the software calc_grm (Calus, 2013). $\sigma_{a}^{2}$ was estimated with a model excluding the effect of Marker, and was fixed in model 1. $e$ is the random residual effect and is assumed to be distributed as $N \sim\left(0, I \sigma_{e}^{2}\right)$, where $I$ is the identity matrix and $\sigma_{e}^{2}$ is the residual variance.

The most promising genomic region with multiple signals at $-\log _{10}(P$-value $) \geq 6$ was imputed from the BovineHD genotypes to sequence level, and a region-wide association study (RWAS) was performed.

\section{Imputation}

Imputation started by checking the BovineHD against the sequenced reference population for inconsistencies using the Conform-gt software (http://faculty.washington.edu/browning/ conform-gt.html). After this check, the 382 cows were imputed from BovineHD genotypes to sequence level for half of a chromosome using Beagle version 4.0 (Browning and Browning, 2007). Beagle version 4.0 was run with the following settings: 50 for phase iterations, 50 for nthreads, and 100 for imputation iterations. To account for the nature of the different variants, we ran three imputations based on different reference populations. These imputations were named as follows: "Nordic-red-specific," "Dairy-specific," and "Common." For the imputation of the "Nordic-red-specific," the reference population used consisted of the 33 sequences belonging to SR and FAY breeds. For the imputation of the "Dairy-specific," the reference population used consisted of the 284 sequences belonging to dairy breeds ( 8 breeds). For the imputation of the "Common," the reference population used consisted of 429 sequences belonging to Nordicred, dairy and beef breeds (15 breeds). Following this approach, each variant was imputed three times based on the three different reference populations, which resulted in different imputation accuracies (Beagle allelic-r2, AR2) for each variant. 
The genotype with the highest imputation accuracy across the three imputations was selected as the best-imputed genotype.

We calculated the average concordance between the imputed genotypes across the three different scenarios of imputation, as implemented in VCFtools version 0.1.12b (Danecek et al., 2011). Subsequently, we combined the best-imputed genotypes into one data set that was used in the RWAS.

\section{RWAS on Imputed Sequences for Half a Chromosome}

A RWAS with imputed sequence data for the most promising region on half a chromosome was run using model 1 . The imputed sequences were filtered to remove poorly imputed genotypes: only variants that were imputed with an AR2 $\geq$ 0.2 were included in the RWAS. Single-marker analyses were run using model 1 with one modification: the variance of the genetic effect $a$ was assumed to be distributed as $N \sim$ $\left(0, \mathbf{G} \mathbf{1} \sigma_{a^{*}}^{2}\right)$, where $\mathbf{G} \mathbf{1}$ is the genomic relationship matrix based on 382 animals and $\sigma_{a^{*}}^{2}$ is the additive genetic variance. The G1matrix was calculated using the software calc_grm (Calus, 2013). The BovineHD genotypes of half chromosome that were used in the imputation to sequence level were not included in the G1matrix calculations. $\sigma_{a^{*}}^{2}$ was calculated before the inclusion of Marker, and was fixed in model 1.

The most significant association from the first RWAS (coined TagSNP1) was subsequently included as a fixed effect in model 1, and a second RWAS was run. For this second RWAS, only the variants with an AR2 $\geq 0.8$ were re-analyzed and considered for further analyses, such as LD calculations and haplotype analyses.

\section{Haplotype Analyses}

The construction of haplotypes started by selecting the SNP moderately to highly correlated with TagSNP1 (LD > 0.5). LD was calculated as the squared correlation between TagSNP1 and all other SNP using PLINK version 1.9 (Purcell et al., 2007). An LD plot was produced using the R-package ggplot2 (Wickham, 2009). Next, we combined these correlated SNP into haplotypes.

For the haplotypes, we produced a phylogenetic tree using the molecular evolutionary genetics analysis (MEGA6) software, version 6.0. The MEGA6 software was developed for comparative analyses of DNA and protein sequences that aim at inferring the molecular evolutionary patterns of genes, genomes, and species over time (Kumar et al., 1994; Tamura et al., 2013). To build the phylogenetic tree, we applied the Neighbor-Joining statistical method (Saitou and Nei, 1987) with a substitution model based on the proportion of nucleotide substitutions per site between nucleotides of loaded sequences. Alignment gaps and missing information gaps were accounted for with the partial-deletion option implemented in the software, and gaps were removed when the number of ambiguous sites $\geq 0.95$.

Subsequently, the phylogenetic tree, all phenotypes and two copies of each haplotypes per cow were supplied to TreeScan software, version 1.0 (Templeton et al., 2005). TreeScan uses the phylogenetic tree built from haplotypes in phenotype-genotype association studies. With its iterative approach, TreeScan cuts in two parts a branch of the phylogenetic tree. For part 1, all haplotypes are grouped, and treated as a single allele, say A. For part 2, all haplotypes are grouped, and treated as a single allele, say $B$. These alleles allow different combinations of genotypes: $\mathrm{AA}, \mathrm{AB}$, and $\mathrm{BB}$. Subsequently, associations between phenotypes and genotypes ( $\mathrm{AA}, \mathrm{AB}$, and $\mathrm{BB}$ ) are statistically tested with the F-statistics of a one-way ANOVA. This iterative approach is repeated until all the branches of the phylogenetic tree have been tested. The null hypothesis considered for the inference of branches (i.e., haplotypes) is of no association between a partition and the trait of interest, which in our case was NC milk. In addition, the following settings were used in TreeScan: the number of simulations to obtain $P$-values for the ANOVA tests $p=5,000$; the significance level $\alpha=0.05$, and the minimum number of individuals required in each observed genotypic class $c=2$. A bipartition was considered as significantly associated to NC milk at $P<0.05$.

\section{Bioinformatics and Candidate Genes}

We used the variant effect predictor (Ve!P) online tool (at http:// www.ensembl.org/info/docs/tools/vep/index.html; McLaren et al., 2010) to determine the effect of the variants (SNPs, insertions, deletions, CNVs or structural variants) on genes, transcripts, and protein sequence, as well as regulatory regions.

\section{RESULTS}

\section{GWAS on BovineHD Genotypes}

The GWAS on BovineHD genotypes identified many significant SNP associated with NC milk after fitting the casein loci (Supplementary Figures 1A-D). The accompanying QQ-plot indicated that a small proportion of SNP were deviating from the $x=y$ line. This smaller proportion of SNP represented the most likely associated SNP among the thousands of non-associated SNP with NC milk. In addition, no important deviations from the $x=y$ line were observed, suggesting no obvious signs of population stratification (Supplementary Figure 2). Fourteen of the many associations were significant at $-\log _{10}(P$-value $)>6$, and they are located on BTA11, BTA13, and BTA18 (Table 1). The most promising region was located on BTA18, and was distributed over a region of seven mega base-pairs (MBP). Because BTA18 showed the most significant association with NC milk after fitting the casein loci, we focused on this chromosome by running a RWAS using imputed sequence data.

\section{Imputation for Half of BTA18}

Before imputation, the inconsistencies between the BovineHD genotypes and the sequence data were strand problems (i.e., 1 for Nordic-red-specific, 815 for Dairy-specific, and 927 for commons), and seven SNP from the BovineHD genotypes not present in the sequence data. All these inconsistencies were set to missing in the BovineHD data, and imputed.

After imputation, the total number of variants in the region between 0-30 MBP on BTA18 increased from 7873 SNP on the BovineHD to 562,432 variants on the sequence level, representing an increase of 71 times in the total number of variants. From the 562,432 imputed variants, $69.3 \%$ were monomorphic (MAF $=0$ ), $24.5 \%$ were polymorphic and AR2 $\geq 0.2$, and $14.3 \%$ 
TABLE 1 | Most significant SNP from genome-wide association study with NC milk ${ }^{\dagger}$ based on BovineHD genotypes in 382 Swedish Red cows.

\begin{tabular}{|c|c|c|c|c|c|}
\hline Chromosome & SNP & Position & $-\log _{10}(P$-value $)$ & $\sigma_{\text {marker }}^{2} \S$ & $\sigma_{\text {marker }}^{2} / \sigma_{\mathrm{p}}^{2 *}$ \\
\hline 11 & rs136987882 & 55787730 & 6.29 & 0.01 & 0.07 \\
\hline 13 & rs136185829 & 47744740 & 6.15 & 0.01 & 0.07 \\
\hline 13 & rs109492822 & 47749851 & 6.15 & 0.01 & 0.07 \\
\hline 13 & rs134756836 & 47754335 & 6.15 & 0.01 & 0.07 \\
\hline 18 & rs137544086 & 9179722 & 6.19 & 0.01 & 0.07 \\
\hline 18 & rs41865365 & 11166809 & 8.77 & 0.01 & 0.09 \\
\hline 18 & rs110267892 & 13136171 & 6.65 & 0.01 & 0.07 \\
\hline 18 & rs109208214 & 13934856 & 10.18 & 0.02 & 0.11 \\
\hline 18 & rs135171892 & 13939170 & 10.18 & 0.02 & 0.11 \\
\hline 18 & rs137827420 & 13943440 & 10.18 & 0.02 & 0.11 \\
\hline 18 & rs137429187 & 13960525 & 10.18 & 0.02 & 0.11 \\
\hline 18 & rs132908573 & 13967910 & 10.18 & 0.02 & 0.11 \\
\hline 18 & rs110637786 & 15017982 & 9.35 & 0.01 & 0.10 \\
\hline 18 & rs110615481 & 15047675 & 6.54 & 0.01 & 0.08 \\
\hline
\end{tabular}

${ }^{\dagger} \mathrm{NC}$ milk as binary trait where $0=$ coagulating milk and $1=$ non-coagulating milk.

$\S_{\sigma_{\text {marker }}^{2}}^{2}=$ marker's variance, computed for each marker as 2 times major allele frequency times minor allele frequency times the square of the allele substitution effect.

${ }^{*}{ }^{2}$ marker $/ \sigma_{p}^{2}=$ proportion of phenotypic variance explained by a marker.

were polymorphic and $\mathrm{AR} 2 \geq 0.8$ (Table 2). After filtering out the monomorphic variants, 137,949 polymorphic variants imputed with an AR2 $\geq 0.2$ were left. This is an increase of more than 17 times in the total number of variants from BovineHD genotypes $(N=7873 \mathrm{SNP})$ to sequence level $(N=$ 137,949 sites). These 137,949 variants originated from the three scenarios as follows: 98,152 variants from the Nordic-red-specific scenario, plus 28,394 variants from the Dairy-specific scenario, plus 11,403 variants from the common scenario. In addition, the 98,152 variants from the Nordic-red-specific scenario are composed of 91,363 SNP, 6753 indels, and 36 multi-allelic variants. The 28,394 variants from the Dairy-specific scenario are composed of 27,113 SNP, 1253 indels, and 28 multi-allelic variants. The 11,403 variants from the common scenario are composed of 10,989 SNP, 401 indels, and 13 multi-allelic variants.

The average concordance was calculated by comparing genotypes imputed in the three different scenarios, and reported sites were alleles in exact match between files. Results indicated that $97.0 \%$ of the imputed genotypes from the Nordic-red-specific scenario were concordant with the Dairyspecific scenario; $96.8 \%$ of the imputed genotypes from the Nordic-red-specific scenario were concordant with the common scenario; and $98.9 \%$ of the imputed genotypes from the Dairy-specific scenario were concordant with the common scenario.

\section{RWAS on Imputed Sequences for Half of BTA18}

A RWAS based on imputed sequences was run for half of BTA18, which corresponds to a genomic region of $30 \mathrm{MBP}$ running from position 0 on bovine genome built UMD 3.1. Throughout this region, a total of 205 variants were significantly associated with NC milk at $-\log _{10}(P$-value $)>6$ and imputed with AR2 $\geq$ 0.8 (Supplementary Table 1). The most significant variants were one indel and two SNP. The indel was rs385975260 occurring at $15.03 \mathrm{MBP}$, and was imputed with AR2 $=0.87$. The first SNP was rs525335650 located at $15.03 \mathrm{MBP}$, and was imputed with $\mathrm{AR} 2=0.87$. The second SNP was rs379827811 located at 15.04 $\mathrm{MBP}$, and was imputed with AR2 $=0.42$. These two SNP and one indel are in perfect LD with each other. We chose rs525335650 among these three imputed variants, since it was the best imputed variant, and tagged it as TagSNP1 (Figure 1A).

After including TagSNP1 as a fixed effect in model 1, a total of 80,206 variants with an AR2 $\geq 0.8$ were re-analyzed. We reanalyzed these 80,206 imputed variants instead of the 137,949 imputed variants to reduce potential false-positive associations with NC milk caused by imputation errors. After accounting for TagSNP1 in model 1 as fixed effect, no remaining associations were found (Figure 1B).

\section{Haplotype Analyses}

A total of 129 SNP plus 17 indels in LD with TagSNP1 (Figure 2) were combined into 59 haplotypes. These 59 haplotypes were the basis to build a phylogenetic tree, for which each branch represented one unique haplotype segregating in the SR cow population (Figure 3A). The iterative inference of haplotypes using TreeScan occurred by, for example, cutting the phylogenetic tree in two parts at branch "A," where haplotypes 38 and 58 were grouped in one part, while all other haplotypes were grouped in the other part. The parts were then tested against each other. After all branches of the tree were tested, associations with NC milk were: branch " $\mathrm{A}$ " at $P=0.002$; haplotype 38 at $P=0.03$; and, haplotype 58 at $P=0.03$ (Figure 3A). Next, we scrutinized in depth the sequences of haplotypes 38 and 58, and we found they have three SNP in common. When comparing haplotypes 38 and 58 with haplotypes 13, 20, 29, and 39 (Figure 3B), haplotypes 38 and 58 differed from the other haplotypes at these exact same three SNP. Interestingly, these three SNP shared by haplotypes 38 and 58 are quite close to our TagSNP1 (Figure 3B). 
TABLE 2 | Distribution of the average accuracy of imputation (AR2) per ranges of minor allele frequency (MAF), and the number of markers (as counts and in percentage) for the three scenarios of imputation.

\begin{tabular}{|c|c|c|c|c|c|c|c|c|c|}
\hline \multirow{2}{*}{ MAF } & \multirow{2}{*}{$\mathrm{AR2}^{\dagger}$} & \multicolumn{2}{|c|}{ Nordic-red specific } & \multicolumn{2}{|c|}{ Dairy-specific } & \multicolumn{2}{|c|}{ Common } & \multicolumn{2}{|c|}{ Total number of variants } \\
\hline & & Average AR2 & $\mathrm{N} 1^{\S}$ & Average AR2 & $\mathrm{N} 2^{*}$ & Average AR2 & $\mathrm{N3}^{\mathrm{C}}$ & $\mathbf{N}^{¥}$ & (\%) \\
\hline \multirow[t]{3}{*}{0} & All & 0.00 & 389,518 & 0.00 & 94 & 0.00 & 54 & 389,666 & 69.3 \\
\hline & $\geq 0.2$ & - & 0 & 0.31 & 4 & 0.31 & 0 & 4 & 0.0 \\
\hline & $\geq 0.8$ & - & - & - & - & - & - & - & - \\
\hline \multirow[t]{3}{*}{$0-0.1$} & All & 0.42 & 28,346 & 0.37 & 17,720 & 0.34 & 9,547 & 55,613 & 9.9 \\
\hline & $\geq 0.2$ & 0.72 & 16,772 & 0.62 & 11,266 & 0.59 & 5,861 & 33,899 & 6.0 \\
\hline & $\geq 0.8$ & 0.94 & 9,467 & 0.91 & 2,748 & 0.90 & 1,082 & 13,297 & 2.4 \\
\hline \multirow[t]{3}{*}{$0.1-0.2$} & All & 0.69 & 23,425 & 0.63 & 6,951 & 0.61 & 2,774 & 33,150 & 5.9 \\
\hline & $\geq 0.2$ & 0.76 & 20,922 & 0.70 & 6,136 & 0.67 & 2,462 & 29,520 & 5.2 \\
\hline & $\geq 8$ & 0.94 & 12,994 & 0.92 & 2,329 & 0.91 & 761 & 16,084 & 2.9 \\
\hline \multirow[t]{3}{*}{$0.2-0.3$} & All & 0.75 & 22,765 & 0.70 & 4,593 & 0.68 & 1,467 & 28,825 & 5.1 \\
\hline & $\geq 0.2$ & 0.80 & 21,235 & 0.75 & 4,075 & 0.73 & 1,291 & 26,601 & 4.7 \\
\hline & $\geq 0.8$ & 0.94 & 14,609 & 0.92 & 2,049 & 0.92 & 412 & 17,070 & 3.0 \\
\hline \multirow[t]{3}{*}{$0.3-0.4$} & All & 0.78 & 21,900 & 0.74 & 4,422 & 0.71 & 1,205 & 27,527 & 4.9 \\
\hline & $\geq 0.2$ & 0.83 & 20,429 & 0.80 & 3,759 & 0.78 & 991 & 25,179 & 4.5 \\
\hline & $\geq 0.8$ & 0.95 & 15,189 & 0.93 & 2,186 & 0.92 & 392 & 17,767 & 3.2 \\
\hline \multirow[t]{3}{*}{$0.4-0.5$} & All & 0.67 & 22,731 & 0.62 & 3,854 & 0.59 & 1,066 & 27,651 & 4.9 \\
\hline & $\geq 0.2$ & 0.83 & 18,794 & 0.79 & 3,154 & 0.78 & 798 & 22,746 & 4.0 \\
\hline & $\geq 0.8$ & 0.95 & 13,937 & 0.93 & 1,779 & 0.92 & 272 & 15,988 & 2.8 \\
\hline \multirow[t]{3}{*}{ Total } & All & 0.55 & 508,685 & 0.51 & 37,634 & 0.49 & 16,113 & 562,432 & 100.0 \\
\hline & $\geq 0.2$ & 0.79 & 98,152 & 0.73 & 28,394 & 0.71 & 11,403 & 137,949 & 24.5 \\
\hline & $\geq 0.8$ & 0.94 & 66,196 & 0.92 & 11,091 & 0.91 & 2,919 & 80,206 & 14.3 \\
\hline
\end{tabular}

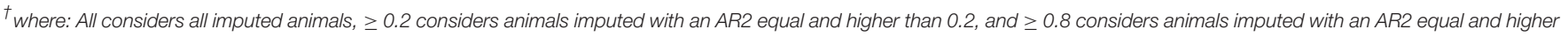
than 0.8 .

$\S N 1$, total number of markers for the Nordic-Red specific scenario.

${ }^{*} N 2$, total number of markers for the Dairy-specific scenario.

${ }^{\circledR} \mathrm{N} 3$, total number of markers for the Common scenario.

$¥ N$, sum of markers for all three imputation scenarios $(N 1+N 2+N 3)$.

\section{Bioinformatics and Candidate Genes}

According to Ve!P, the 129 SNP plus the 17 indels, which included our TagSNP1, were distributed as follows: $32 \%$ of intron variants; $26 \%$ of downstream gene variants, $25 \%$ of upstream gene variants; $12 \%$ of intergenic variants; $4 \%$ of $3^{\prime}$ UTR variants; $1 \%$ of synonymous variants, and $1 \%$ of missense variants. In summary, $67 \%$ of these 129 SNP plus 17 indels were synonymous variants without changes to the encoded amino acids. The remaining 33\% were missense variants with changes in one or more bases to the encoded amino acid.

In addition, Ve!P showed that our QTL region on BTA18 contains seven genes (Table 3), of which one is a validated gene and six are provisional genes. These seven genes are: validated carbonic anhydrase VA, mitochondrial (CA5A) gene; BTG3 associated nuclear protein $(\boldsymbol{B A N P})$ gene; cytochrome b245, alpha polypeptide (CYBA) gene; mevalonate (diphospho) decarboxylase, mRNA ( $M V D)$ gene; snail family zinc finger 3 (SNAI3) gene; ring finger protein 166 (RNF166) gene; and, vacuolar protein sorting 35 homolog, mRNA (VPS35) gene.
In addition, the $C A 5 A$ gene is located within a copy number variation.

The genomic position of the three strongest associations with NC milk on BTA18 are shown in Supplementary Figure 3A. Of these associations, rs379827811 is an intron variant in the VPS35 gene. According to Ve!P, rs379827811 is upstream to 14 missense variants, 1 synonymous variant, 1 stop gained variant and 1 splice region variant (Supplementary Figure 3B).

The three SNP shared by haplotypes 38 and 58 identified in the haplotype analyses are intergenic variants located between 20.5 and 31.2 kilo base-pairs (kbp) downstream to the VPS35 gene.

\section{DISCUSSION}

In the present study, we used the same phenotypes and BovineHD genotypes as in Gustavsson et al. (2014a) to perform a GWAS with NC milk, and we further fine-mapped a genomic region on half of BTA18 using imputed sequences. This genomic 


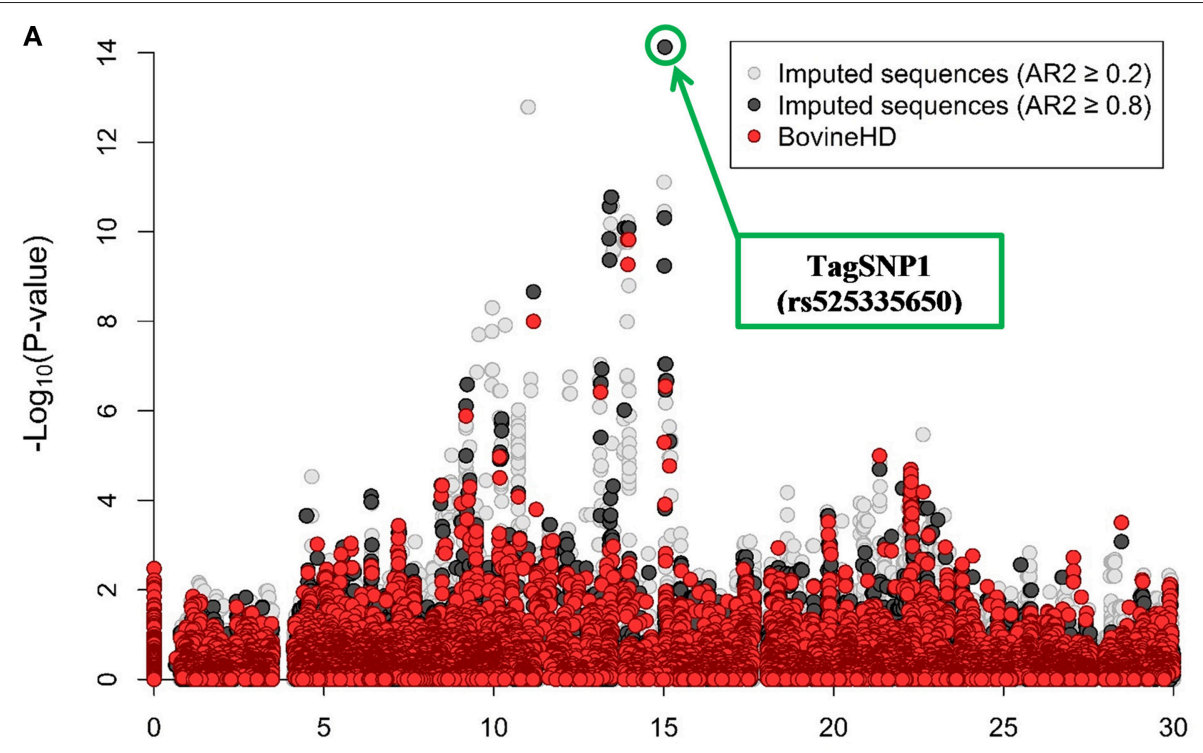

B

Position in mega base-pairs

FIGURE 1 | Region-wide association study (RWAS) with non-coagulating (NC) milk in $\mathbf{3 8 2}$ Swedish Red cows. (A) RWAS based on 137,949 polymorphic imputed variants overlaid with the BovineHD genotypes for half of BTA18. In light gray, imputed variants with accuracy of imputation (AR2) $\geq 0.2$. In black, imputed variants with AR2 $\geq 0.8$. "TagSNP1" as most significant association. (B) RWAS after correcting for TagSNP1. In black, imputed variants with AR2 $\geq 0.8$ ( $N=80,206$ variants).

region is distributed over seven $\mathrm{MBP}$ on $\mathrm{BTA} 18$, and is strongly associated with NC milk. At least one QTL could be fine-mapped using imputed sequences. In addition, we conducted haplotype analyses to disentangle the occurrence of multiple QTL in strong LD within this region. At last, we identified potential candidate genes within this QTL region.

\section{GWAS on BovineHD Genotypes}

The GWAS on BovineHD genotypes showed significant associations with NC milk distributed over seven mega base-pairs
(MBP) on BTA18 (Table 1). These seven MBP explain large fractions of the phenotypic variation in NC milk, ranging from 7 to $11 \%$. Tyrisevä et al. (2008) performed a genome scan to map non-coagulation of milk in 477 genotyped FAY cows. Their study used microsatellite markers and identified a QTL located around $17 \mathrm{MBP}$ on BTA18. Their QTL is very close to the seven MBP region identified in our study. The methodology used by Tyrisevä et al. (2008) is different from the present study. It is important to note that the study by Tyrisevä et al. (2008) is based on a linkage study within sire families 


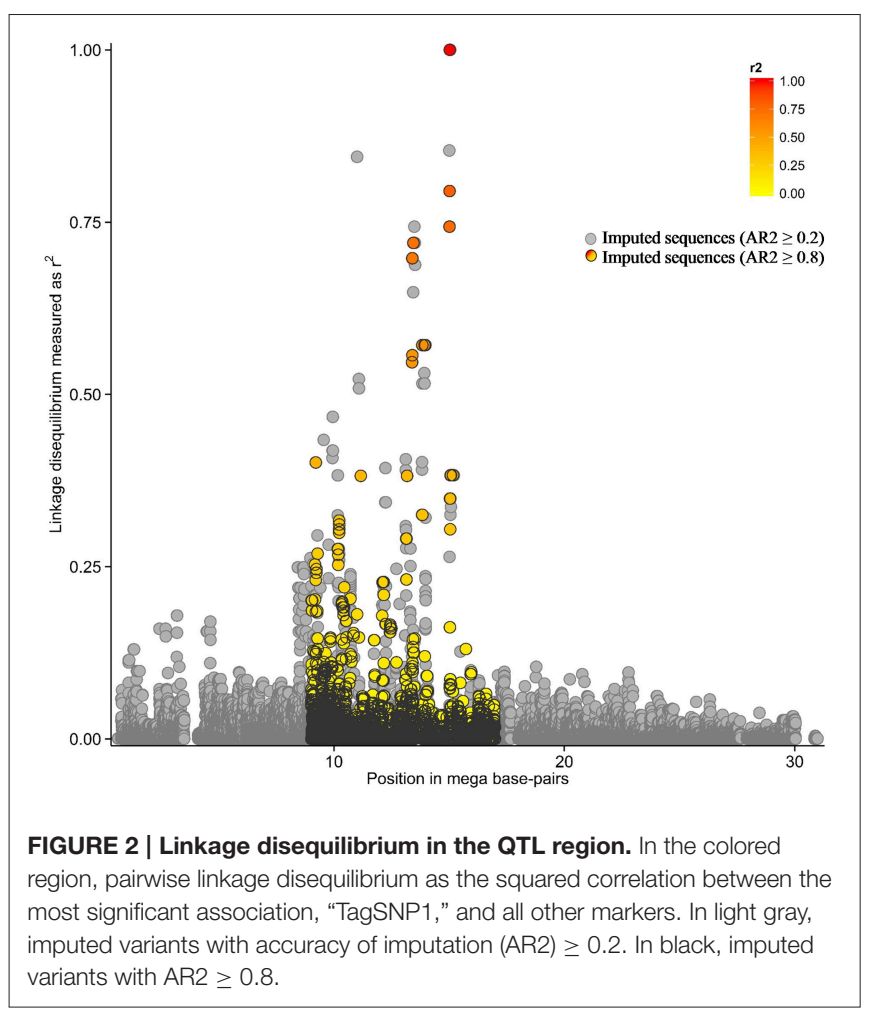

with pooled DNA of cows with extreme phenotypes, and our study is based on an association analysis of genotyped cows with scored phenotypes. Both methodologies have the common goal of pointing out the potential candidate genes associated with a trait of interest, and, despite the differences between both studies, a similar genomic region was associated with NC milk.

Eleven significant associations found by our GWAS were in agreement with associations found by the GWAS of Gregersen et al. (2015), who studied MCP properties but not NC milk. This agreement occurred with the following two traits: rennet gel strength measured $30 \mathrm{~min}$ after chymosin addition (G'30), and rennet coagulation time (CTrennet). For G'30, associations agreed on BTA1, BTA13, BTA18, and BTA22. More specifically, these associations were: four SNP located between 70.75 and 70.90 MBP on BTA1; five SNP located between 58.10 and 58.14 MBP on BTA13; one SNP at 13.13 MBP on BTA18; and one SNP located at 19.35 MBP on BTA22. The strong negative genetic correlation between NC milk and G'30 (-0.82; Gustavsson et al., 2014a) is likely to explain the agreement of results between both studies regarding G'30. For CTrennet, associations agreed on BTA18, and these were: one SNP located at 11.16 MBP, and one SNP located at 11.65 MBP. Gregersen et al. (2015) used (logtransformed) CTrennet in their GWAS, whereas we analyzed NC milk, a trait derived from CTrennet. Despite the use of different but CTrennet-related traits, it was unexpected to find only two associations in agreement between both studies. A reason for this little agreement might be caused by our approach to analyze NC milk, which dealt with the right-censored nature of coagulation time in a more suitable way (Cecchinato and Carnier, 2011).
An important aspect of our GWAS on BovineHD genotypes was the analyses of NC milk as a normally distributed trait despite its binary nature. Cecchinato and Carnier (2011) were the first authors to suggest this approach because NC milk samples have been consistently excluded from most analyses when observed (e.g., Ikonen et al., 2004; Gregersen et al., 2015). Cecchinato and Carnier (2011) showed that statistical models have difficulties to correctly account for NC milk, and suggested to score NC milk as a binary trait and include it as a normally distributed trait in linear mixed models. This option allows for analyses of NC milk without the exclusion of information. Following this approach, Gustavsson et al. (2014a) included NC milk as a binary trait in their analyses, and estimated genetic parameters for rennetinduced coagulation properties in SR cows. In addition, the inclusion of NC milk as a binary trait in our study could be one of the reasons why little overlap was found with the study by Gregersen et al. (2015) regarding CTrennet.

Besides their GWAS, Gregersen et al. (2015) found a suggestive QTL for the log-transformed G'30 trait by haplotypes analyses. This suggestive QTL was found in the interval located between 11.65 and 22.34 MBP on BTA18. Although, not significant in their study, this suggestive QTL interval is in agreement with 9 out of 10 of our most significant SNP associated with NC milk on BTA18 (Table 1). In addition, the top SNP indicated by Gregersen et al. (2015) at 11.16 MBP is among our most significant SNP associated with NC milk.

Breeding for higher protein content in SR cows might lead to problems in the foreseeable future, suggested by the moderate, yet unfavorable genetic correlation between NC milk and protein content (Gustavsson et al., 2014a). Our main goal was to disentangle the effects of genetic variants of milk protein fractions from other genetic variants associated with NC milk. For this reason, we included a multi-locus genotype that combined the genetic variants of the main milk protein fractions (i.e., $\alpha s 1-\beta-\kappa-C N$; "CNcluster") in our model. Bittante et al. (2012) reviewed the most important genetic factors that affect $\mathrm{MCP}$, indicating that $\mathrm{MCP}$, including NC milk, are strongly influenced by variable proportions, and genetic variants of milk protein fractions (especially of $\kappa-\mathrm{CN}$ ). These milk protein fractions, mainly representing caseins, are encoded on BTA6 and thus, the recombination among alleles is small (Bittante et al., 2012). In contrast, Tyrisevä et al. (2008) did not find significant associations between NC milk and the casein loci. In the present study, the casein loci were included as part of the design of our GWAS with NC milk, resulting in significant associations that are independent from the casein loci. This means that genes found by our study represent a new set of genes compared with the genes of the casein loci known to influence the prevalence of NC milk (e.g., Jensen et al., 2012; Gustavsson et al., 2014b).

\section{Imputation}

Imputation of SR cows was quite challenging because most of the variants were poorly imputed at sequence level when directly using the 429 WGS as reference population. As pointed out by Bouwman and Veerkamp (2014), breed-specific variants are best imputed by using a large single-breed reference population. This 
A

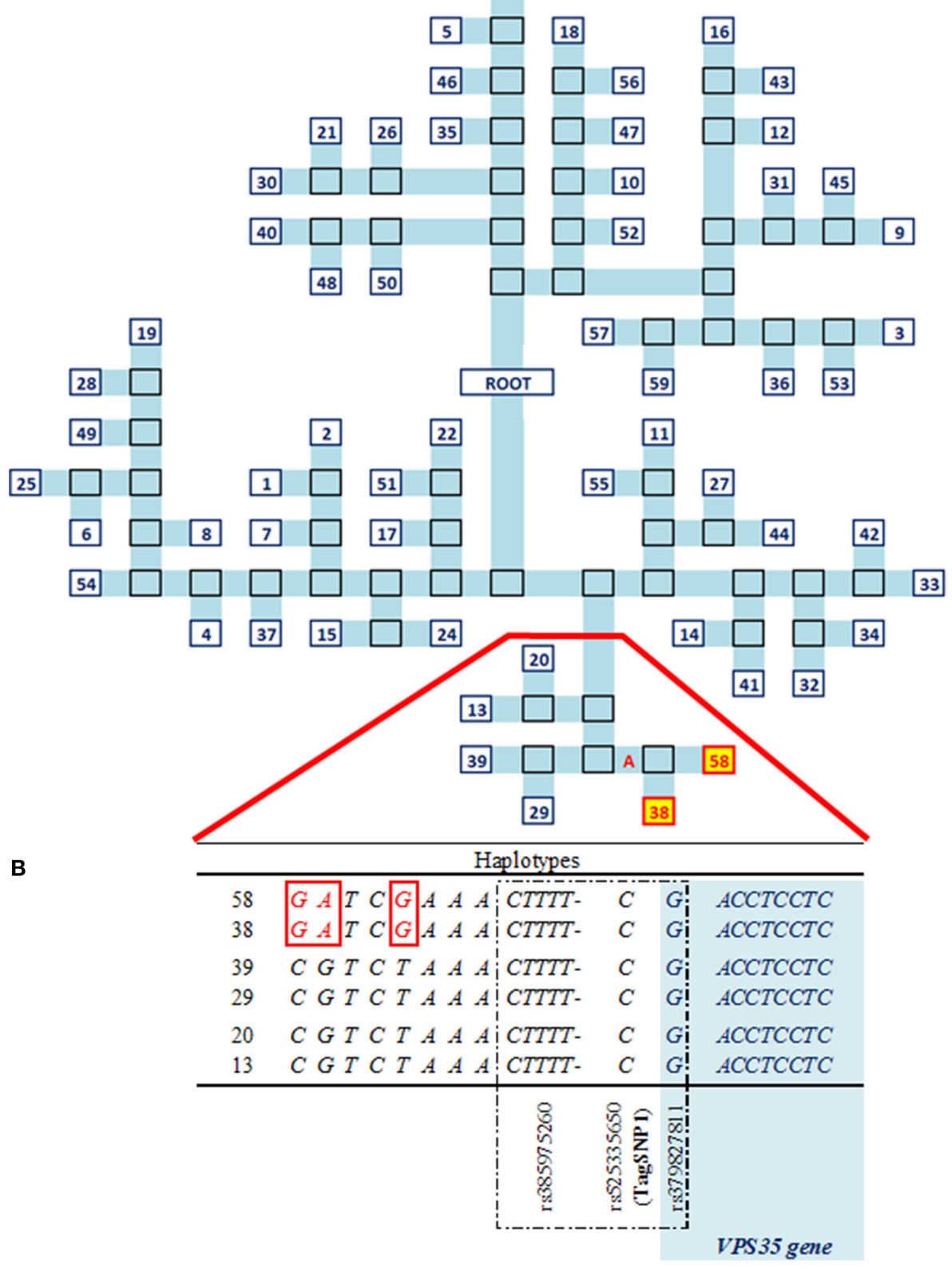

FIGURE 3 | Haplotypes analyses characterizing the QTL region in SR cows. (A) Phylogenetic tree of the 59 unique haplotypes, numbered in blue. In light blue, a branch of the tree. In black borders, bipartitions. In red and yellow, significant haplotypes at $P<0.05$. (B) Relevant part of the sequences of significant vs. other haplotypes. In red, differences between haplotypes. Dashed in black, strongest associations including TagSNP1. In light blue, the VPS35 gene.

suggestion would mean that only 33 out of the 429 WGS would be of interest to impute our 382 SR cows to sequence level. The challenge of imputing a small breed like SR was overcome by running three different scenarios of imputation, and each time with a different reference population. The genotype that had the best imputation accuracy across the three scenarios was selected as the best-imputed genotype. The average accuracies of imputation using our approach were 0.79 for variants imputed with $\mathrm{AR} 2 \geq 0.2$, and 0.93 for variants imputed with AR2 $\geq$ 0.8. While this is a slightly ad-hoc approach, there was good concordance between the three imputation scenarios and our subsequent focus on variants with AR2 $\geq 0.8$ adds further rigor to our analyses.

\section{RWAS on Imputed Sequences for Half of BTA18}

The RWAS on imputed sequences for half of BTA18 revealed many significant associations with NC milk (Supplementary Table 1). One of our three strongest associations, TagSNP1, 
TABLE 3 | Details about candidate genes identified in the QTL region.

\begin{tabular}{llcc}
\hline Genes & Identifier & \multicolumn{1}{c}{ Location } & $\begin{array}{c}\text { Numbers } \\
\text { of } \\
\text { variants }\end{array}$ \\
\hline CA5A & ENSBTAG00000010151 & chr18: 13,356,215-13,445,854 & 8 \\
BANP & ENSBTAG00000023745 chr18: 13,425,303-13,493,366 & 3 \\
CYBA & ENSBTAG00000003895 chr18: 13,931,107-13,938,075 & 40 \\
MVD & ENSBTAG00000012059 chr18: 13,938,827-13,945,489 & $72^{*}$ \\
SNA/3 & ENSBTAG00000017528 chr18: 13,958,995-13,964,622 & $36^{\star *}$ \\
RNF166 & ENSBTAG00000020942 chr18: 13,969,303-13,977,633 & 3 \\
VPS35 & ENSBTAG00000002493 chr18: 15,038,821-15,066,463 & 2 \\
\hline
\end{tabular}

*40 of these 72 variants in the MVD gene overlap with variants in the CYBA gene. These are: 26 downstream variants in the MVD gene corresponding to 16 introns, 1 synonymous, and 9 upstream variants in the CYBA gene; and seven $3^{\prime}$ UTR, 1 synonymous, 5 intron, and 1 missense variants in the MVD gene corresponding to upstream variants in the CYBA gene ** 5 of these 36 hits are downstream gene variants in the SNAI3 gene that correspond to upstream gene variants in the RNF166 gene.

explained almost $34 \%$ of the genetic variation and $14 \%$ of the phenotypic variance in NC milk (Figures 1A,B). This large fraction of genetic variance explained by TagSNP1 is independent of the casein loci located on BTA6. Altogether, these findings strongly suggest the existence of at least one causal variant in our focus region distributed over seven MBP associated with NC milk. It might be plausible that one causal variant, i.e., 1 QTL is associated with NC milk in our focus region, although we cannot exclude the presence of multiple QTL in strong LD associated with NC milk in our focus region. Similar findings were found by Daetwyler et al. (2014) and Sahana et al. (2014). In their GWAS with imputed sequences, the considerable number of significant variants closely linked to each other increased the complexity of identifying a causal variant. In our study, we performed haplotype analyses to answer whether one or multiple QTL were present in the seven MBP.

\section{Haplotype Analyses}

Among the many advantages of haplotype over single-variant analyses (Balding, 2006), two of them are: (a) haplotype analyses naturally account for the correlated structure between variants because all the genetic variation in a population is transmitted from parent to offspring through haplotypes (Clark, 2004); and (b) haplotype analyses reduce the number of parameters tested in association studies as compared with single-variant analyses (e.g., Clark, 2004; Balding, 2006). In contrast, a "tagging" strategy would reduce the power gained from using haplotypes per se (Balding, 2006). In our study, this limitation was dealt with by using the TreeScan approach (Templeton et al., 2005). TreeScan considered two aspects simultaneously: the correlated structure of variants closely linked to each other, and the origin of this haplotype in the population through a phylogenetic tree. Using the TreeScan approach, 2 out of the 59 haplotypes were found to be associated with NC milk in our QTL region (Figure 3A). The two significant haplotypes had three SNP in common, and these SNP are located from 13.7 to $24.4 \mathrm{kbp}$ apart from
TagSNP1 (Figure 3B). These findings support the presence of one QTL influencing NC milk in our focus region. Nonetheless, the task of identifying the causal variant remains challenging. According to Vasemägi and Primmer (2005), when an association between TagSNP1 and the causal variant is found, other linked associations can be responsible for the variation in the trait of interest. This might be our case since TagSNP1 was one out of three closely linked variants strongly associated with NC milk.

\section{Bioinformatics and Candidate Genes}

Our three strongest association with NC milk are composed of one indel and two SNP. One of these two SNP (rs379827811) is an intron variant located between 15.04 MBP within the VPS35 gene (Figure 3B, Supplementary Figures 3A,B). In humans, the VPS35 gene is a component of the retromer complex that mediates endosome-to-Golgi retrieval of membrane proteins such as the cation-independent mannose 6-phosphate receptor. According to Malik et al. (2015), cargo-selective sorting is important for the correct sub-cellular destination of membrane proteins. The retromer complex mediated by VPS35 gene seems to promote the recycling of specific membrane proteins, such as $\beta 2$ - adrenergic receptor and the glucose transporter GLUT1, directly back to plasma membrane (Seaman et al., 2013). It is important to mention that GLUT1 is the major glucose transporter in the basal membrane of epithelial cells and, in the mice mammary gland, its expression was increased when greater demand for glucose for the synthesis of lactose was needed (Anderson et al., 2007). If the recycling mechanism of the retromer complex is defective, it is possible that not enough membrane proteins are recycled, and in turn, are not available for milk synthesis.

A mutation in the VPS35 gene has been associated with Parkinson's disease (Zavodszky et al., 2014). In mice-models for Parkinson's disease, a VPS35 deficiency could contribute to retinal ganglion neuro-degeneration, leading to the blindness of many retinal degenerative disorders (Liu et al., 2014). In addition, Lemay et al. (2013) shows that the VPS35 gene is expressed throughout lactation in humans, which include colostrum, transitional, and mature milk, after they sequenced the mRNA found in milk fat layer. In Arabidopsis, the VPS35 gene has been associated with protein sorting and is involved in the plant growth and leaf senescence (Yamazaki et al., 2008). In addition, Munch et al. (2015) shows that a dysfunction in the VPS35 gene can contribute to immune-associated cell death in Arabidopsis. In cattle, Lemay et al. (2009) classified the mammary gene sets according to their condition and their developmental specific-stage, and showed that the VPS35 gene belonged to the mammary gene sets of pre-parturient and of lactating cows. The VPS35 gene has not been associated to NC milk yet.

\section{CONCLUSIONS}

The GWAS on BovineHD genotypes found significant associations with NC milk distributed over seven MBP on BTA18 for SR cows. These seven MBP contained 14 SNP that 
explained from 7 to $11 \%$ of phenotypic variation in NC milk. This large proportion of explained phenotypic variance is independent of the casein loci. To further characterize these seven MBP, we ran a region-wide association study with imputed sequences. The significance of the associations increased from $-\log _{10}(P$-value $)=10.18$ on BovineHD genotypes to $-\log _{10}(P$ value $)=14.12$ on imputed sequences. $\mathrm{NC}$ milk in SR cows was influenced by at least one QTL within these seven MBP. A haplotype analyses identified 2 haplotypes that differed from the other 57 haplotypes at three SNP. These three SNP were located near to the strongest association identified by the region-wide association study with imputed sequences. For BTA18, haplotype analyses support the existence of one QTL underlying NC milk in SR cows. A candidate gene of interest is the VPS35 gene, for which one of our strongest association is an intronic SNP in this gene. It has been suggested that the VPS35 gene is involved in the recycling of specific membrane proteins, such as $\beta 2$ adrenergic receptor and the glucose transporter GLUT1. The VPS35 gene belongs to the mammary gene sets of pre-parturient and of lactating cows, and has not been associated to NC milk yet.

\section{ETHICS STATEMENT}

The study was approved by the Swedish Board of Agriculture, Gothenburg ethical committee, on 22 March 2010 (Registration number 51-2010).

\section{REFERENCES}

Anderson, S. M., Rudolph, M. C., McManaman, J. L., and Neville, M. C. (2007). Secretory activation in the mammary gland: it's not just about milk protein synthesis. Breast Cancer Res. 9, 204-217. doi: 10.1186/ bcr 1653

Aulchenko, Y. S., Ripke, S., Isaacs, A., and Van Duijn, C. M. (2007). GenABEL: an R library for genome-wide association analysis. Bioinformatics 23, 1294-1296. doi: 10.1093/bioinformatics/btm 108

Auldist, M. J., Johnston, K. A., White, N. J., Fitzsimons, W. P., and Boland, M. J. (2004). A comparison of the composition, coagulation characteristics and cheesemaking capacity of milk from Friesian and Jersey dairy cows. J. Dairy Res. 71, 51-57. doi: 10.1017/S0022029903006575

Balding, D. J. (2006). A tutorial on statistical methods for population associationstudies. Nat. Rev. Genet. 7, 781-791. doi: 10.1038/nrg1916

Bittante, G., Penasa, M., and Cecchinato, A. (2012). Invited review: genetics and modeling of milk coagulation properties. J. Dairy Sci. 95, 6843-6870. doi: $10.3168 /$ jds.2012-5507

Bouwman, A. C., and Veerkamp, R. F. (2014). Consequences of splitting wholegenome sequencing effort over multiple breeds on imputation accuracy. BMC Genet. 15:105. doi: 10.1186/s12863-014-0105-8

Browning, S. R., and Browning, B. L. (2007). Rapid and accurate haplotype phasing and missing-data inference for whole-genome association studies by use of localized haplotype clustering. Am. J. Hum. Genet. 81, 1084-1097. doi: $10.1086 / 521987$

Calus, M. P. L. (2013). Calc_grm-A programme to compute pedigree, genomic, and combined relationship matrices. Wageningen: Animal Breeding and Genomics Centre, Wageningen UR Livestock Research.

Cassandro, M., Comin, A., Ojala, M., Dal Zotto, R., De Marchi, M., Gallo, L., et al. (2008). Genetic parameters of milk coagulation properties and their relationships with milk yield and quality traits in Italian Holstein cows. J. Dairy Sci. 91, 371-376. doi: 10.3168/jds.2007-0308

\section{AUTHOR CONTRIBUTIONS}

MG and MP coordinated the data collection and analysis of milk samples. MG, MP, WF, and DJ designed and supervised the study. SD, DJ, and WF analyzed the data and interpreted the results. SD, MG, DJ, MP, WF wrote the manuscript. All authors revised and accepted the final version of the manuscript.

\section{ACKNOWLEDGMENTS}

SD currently benefits from a joint-grant from the European Commission [within the framework of the Erasmus-Mundus joint doctorate "EGS-ABG" (Paris, France) and Breed4Food (a public-private partnership in the domain of animal breeding and genomics and CRV]. Further, the authors wish to thank the Swedish Farmer's Foundation for Agricultural Research (SLF), Stockholm, Sweden for financial support as well as Dr. Frida Gustavsson, Lund University, Sweden for milk collection and analyses of coagulation data. DJK and WFF acknowledges Mistra Biotech, a research program financed by Mistra-Stiftelsen för miljoöstrategisk forskning and SLU.

\section{SUPPLEMENTARY MATERIAL}

The Supplementary Material for this article can be found online at: http://journal.frontiersin.org/article/10.3389/fgene. 2016.00057

Cecchinato, A., and Carnier, P. (2011). Short communication: statistical models for the analysis of coagulation traits using coagulating and noncoagulating milk information. J. Dairy Sci. 94, 4214-4219. doi: 10.3168/jds.20103911

Cecchinato, A., De Marchi, M., Gallo, L., Bittante, G., and Carnier, P. (2009). Mid-infrared spectroscopy predictions as indicator traits in breeding programs for enhanced coagulation properties of milk. J. Dairy Sci. 92, 5304-5313. doi: 10.3168/jds.2009-2246

Cecchinato, A., Penasa, M., De Marchi, M., Gallo, L., Bittante, G., and Carnier, P. (2011). Genetic parameters of coagulation properties, milk yield, quality, and acidity: estimated using coagulating milk and noncoagulating information in Brown Swiss and Holstein cows. J. Dairy Sci. 94, 4205-4213. doi: 10.3168/jds.2010-3913

Chilliard, Y., Ferlay, A., and Doreau, M. (2001). Effect of different types of forages, animal fat or marine oils in cow's diet on milk fat secretion and composition, especially conjugated linoleic acid (CLA) and polyunsaturated fatty acids. Livest Prod. Sci. 70, 31-48. doi: 10.1016/S0301-6226(01)00 196-8

Clark, A. G. (2004). The role of haplotypes in candidate-gene studies. Genet. Epidemiol. 27, 321-333. doi: 10.1002/gepi.20025

Daetwyler, H. D., Capitan, A., Pausch, H., Stothard, P., van Binsbergen, R., Brøndum, R. F., et al. (2014). Whole-genome sequencing of 234 bulls facilitates mapping of monogenic and complex traits in cattle. Nat. Genet. 46, 858-865. doi: 10.1038/ng.3034

Danecek, P., Auton, A., Abecasis, G., Albers, C. A., Banks, E., DePristo, M. A., et al. (2011). The variant call format and VCFtools. Bioinformatics 27, 2156-2158. doi: 10.1093/bioinformatics/btr330

De Marchi, M., Dal Zotto, R., Cassandro, M., and Bittante, G. (2007). Milk coagulation ability of five dairy cattle breeds. J. Dairy Sci. 90, 3986-3992. doi: $10.3168 /$ jds.2006-627

Druet, T., Macleod, I. M., and Hayes, B. J. (2014). Toward genomic prediction from whole-genome sequence data: impact of sequencing design on genotype 
imputation and accuracy of predictions. Heredity (Edinb). 112, 39-47. doi: 10.1038/hdy.2013.13

Frederiksen, P. D., Andersen, K. K., Hammershøj, M., Poulsen, H. D., Sørensen, J., Bakman, M., et al. (2011). Composition and effect of blending of noncoagulating, poorly coagulating, and well-coagulating bovine milk from individual Danish Holstein cows. J. Dairy Sci. 94, 4787-4799. doi: 10.3168/jds.2011-4343

Gilmour, A. R., Gogel, B., Cullis, B., and Thompson, R. (2009). ASReml User Guide, Release 3.0. Hemel Hempstead: VSN International Ltd.

Gregersen, V. R., Gustavsson, F., Glantz, M., Christensen, O. F., Stålhammar, H., Andrén, A., et al. (2015). Bovine chromosomal regions affecting rheological traits in rennet-induced skim milk gels. J. Dairy Sci. 98, 1261-1272. doi: 10.3168/jds.2014-8136

Gustavsson, F., Buitenhuis, A. J., Glantz, M., Stålhammar, H., Lindmark-Månsson, H., Poulsen, N. A., et al. (2014b). Impact of genetic variants of milk proteins on chymosin-induced gelation properties of milk from individual cows of Swedish Red dairy cattle. Int. Dairy J. 39, 102-107. doi: 10.1016/j.idairyj.2014. 05.007

Gustavsson, F., Glantz, M., Poulsen, N. A., Wadsö, L., Stålhammar, H., Andrén, A., et al. (2014a). Genetic parameters for rennet- and acid-induced coagulation properties in milk from Swedish Red dairy cows. J. Dairy Sci. 97, 5219-5229. doi: $10.3168 /$ jds.2014-7996

Hallén, E., Allmere, T., Näslund, J., Andrén, A., and Lundén, A. (2007). Effect of genetic polymorphism of milk proteins on rheology of chymosininduced milk gels. Int. Dairy J. 17, 791-799. doi: 10.1016/j.idairyj.2006. 09.011

Hallén, E., Lundén, A., Tyrisevä, A. M., Westerlind, M., and Andrén, A. (2010). Composition of poorly and non-coagulating bovine milk and effect of calcium addition. J. Dairy Res. 77, 398-403. doi: 10.1017/S00220299100 00671

Ikonen, T., Morri, S., Tyrisevä, A.-M., Ruottinen, O., and Ojala, M. (2004). Genetic and phenotypic correlations between milk coagulation properties, milk production traits, somatic cell count, casein content, and $\mathrm{pH}$ of milk. J. Dairy Sci. 87, 458-467. doi: 10.3168/jds.S0022-0302(04)73185-9

Jensen, H. B., Poulsen, N. A., Andersen, K. K., Hammershøj, M., Poulsen, H. D., and Larsen, L. B. (2012). Distinct composition of bovine milk from Jersey and Holstein-Friesian cows with good, poor, or noncoagulation properties as reflected in protein genetic variants and isoforms. J. Dairy Sci. 95, 6905-6917. doi: $10.3168 /$ jds.2012-5675

Kumar, S., Tamura, K., and Nei, M. (1994). MEGA: Molecular Evolutionary Genetics Analysis software for microcomputers. Comput. Appl. Biosci. 10, 189-191. doi: 10.1093/bioinformatics/10.2.189

Lemay, D. G., Ballard, O. A., Hughes, M. A., Morrow, A. L., Horseman, N. D., and Nommsen-Rivers, L. A. (2013). RNA sequencing of the human milk fat layer transcriptome reveals distinct gene expression profiles at three stages of lactation. PLoS ONE 8:e67531. doi: 10.1371/journal.pone.0067531

Lemay, D. G., Lynn, D. J., Martin, W. F., Neville, M. C., Casey, T. M., Rincon, G., et al. (2009). The bovine lactation genome: insights into the evolution of mammalian milk. Genome Biol. 10:R43. doi: 10.1186/gb-2009-104-r43

Liu, W., Tang, F., Erion, J., and Xiao, H. (2014). VPS35 haploinsufficiency results in degenerative-like deficit in mouse retinal ganglion neurons and impairment of optic nerve injury-induced gliosis. Mol. Brain 7, 1-11. doi: 10.1186/1756-66067-10

LRF Dairy Sweden, (2015). Available online at: http://www.lrf.se/globalassets/ dokument/om-lrf/branscher/lrf-mjolk/statistik/milk_key_figures_sweden.pdf. Accessed on Nov 3rd, 2015.

Malik, B. R., Godena, V. K., and Whitworth, A. J. (2015). VPS35 pathogenic mutations confer no dominant toxicity but partial loss of function in Drosophila and genetically interact with parkin. Hum. Mol. Genet. 24, 6106-6117. doi: 10.1093/hmg/ddv322

McLaren, W., Pritchard, B., Rios, D., Chen, Y., Flicek, P., and Cunningham, F. (2010). Deriving the consequences of genomic variants with the Ensembl API and SNP Effect Predictor. Bioinformatics 26, 2069-2070. doi: 10.1093/bioinformatics/btq330

Meuwissen, T., and Goddard, M. (2010). Accurate prediction of genetic values for complex traits by whole-genome resequencing. Genetics 185, 623-631. doi: 10.1534/genetics.110.116590
Munch, D., Teh, O.-K., Malinovsky, F. G., Liu, Q., Vetukuri, R. R., El Kasmi, F., et al. (2015). Retromer contributes to immunity-associated cell death in Arabidopsis. Plant Cell 27, 463-479 doi: 10.1105/tpc.114.1 32043

Nájera, A. I., De Renobales, M., and Barron, L. J. R. (2003). Effects of $\mathrm{pH}$, temperature, $\mathrm{CaCl} 2$ and enzyme concentrations on the rennet-clotting properties of milk: a multifactorial study. Food Chem. 80, 345-352. doi: 10.1016/S0308-8146(02)00270-4

Nordic Cattle Genetic Evaluation (2013). NAV - Routine Genetic Evaluation of Dairy Cattle - Data and Genetic Models. Available online at: http://www. nordicebv.info/wp-content/uploads/2015/04/General-description_from-oldhomepage_06052015.pdf

Okigbo, L. M., Richardson, G. H., Brown, R. J., and Ernstrom, C. A. (1985a). Variation in coagulation properties of milk from individual cows 1, 2. J. Dairy Sci. 68, 822-828.

Okigbo, L. M., Richardson, G. H., Brown, R. J., and Ernstrom, C. A. (1985b). Casein composition of cow's milk of different chymosin coagulation properties. J. Dairy Sci. 68, 1887-1892.

Ostersen, S., Foldager, J., and Hermansen, J. E. (1997). Effects of stage of lactation, milk protein genotype and body condition at calving on protein composition and renneting properties of bovine milk. J. Dairy Res. 64, 207-219.

Penasa, M., Cassandro, M., Pretto, D., De Marchi, M., Comin, A., Chessa, S. et al. (2010). Short communication: Influence of composite casein genotypes on additive genetic variation of milk production traits and coagulation properties in Holstein-Friesian cows. J. Dairy Sci. 93, 3346-3349. doi: 10.3168/jds.20 10-3164

Purcell, S., Neale, B., Todd-Brown, K., Thomas, L., Ferreira, M. A. R., Bender, D., et al. (2007). PLINK: a tool set for whole-genome association and populationbased linkage analyses. Am. J. Hum. Genet. 81, 559-575. doi: 10.1086/519795

Sahana, G., Guldbrandtsen, B., Thomsen, B., Holm, L.-E., Panitz, F., Brøndum, R. F., et al. (2014). Genome-wide association study using high-density single nucleotide polymorphism arrays and whole-genome sequences for clinical mastitis traits in dairy cattle. J. Dairy Sci. 97, 7258-7275. doi: 10.3168/jds.20 14-8141

Saitou, N., and Nei, M. (1987). The neighbor-joining method: a new method for reconstructing phylogenetic trees. Mol. Biol. Evol. 4, 406-425.

Schwarz, G., and Mumm, H. (1948). The effects of adding calcium chloride potassium nitrate or sodium nitrate to the cheese milk during Tilsit cheese making. Süddeutsche Molkereizeitung 69, 160-161.

Seaman, M. N., Gautreau, A., and Billadeau, D. D. (2013). Retromer-mediated endosomal protein sorting: all WASHed up! Trends Cell Biol. 23, 522-528. doi: 10.1016/j.tcb.2013.04.010

Tamura, K., Stecher, G., Peterson, D., Filipski, A., and Kumar, S. (2013). MEGA6: molecular evolutionary genetics analysis version 6.0. Mol. Biol. Evol. 30, 2725-2729. doi: 10.1093/molbev/mst197

Templeton, A. R., Maxwell, T., Posada, D., Stengård, J. H., Boerwinkle, E., and Sing, C. F. (2005). Tree scanning: a method for using haplotype trees in phenotype/genotype association studies. Genetics 169, 441-453. doi: 10.1534/genetics.104.030080

Tyrisevä, A. M., Elo, K., Kuusipuro, A., Vilva, V., Jänönen, I., Karjalainen, H., et al. (2008). Chromosomal regions underlying noncoagulation of milk in Finnish Ayrshire cows. Genetics 180, 1211-1220. doi: 10.1534/genetics.107.0 83964

Van Hooydonk, A. C. M., Hagedoorn, H. G., and Boerrigter, I. J. (1986). The effect of various cations on the renneting of milk. Neth. Milk Dairy J. 40, 369-390.

Vasemägi, A., and Primmer, C. R. (2005). Invited review - Challenges for identifying functionally important genetic variation:the promise of combining complementary research strategies. Mol. Ecol. 14, 3623-3642. doi: 10.1111/j.1365-294X.2005.02690.x

Wickham, H. (2009). Ggplot2: Elegant Graphics for Data Analysis. New York, NY: Springer Science \& Business Media.

Wilmink, J. B. M. (1987). Adjustment of test-day milk, fat and protein yield for age, season and stage of lactation. Livest Prod. Sci. 16, 335-348. doi: 10.1016/0301-6226(87)90003-0

Yamazaki, M., Shimada, T., Takahashi, H., Tamura, K., Kondo, M., Nishimura, M., et al. (2008). Arabidopsis VPS35, a retromer component, 
is required for vacuolar protein sorting and involved in plant growth and leaf senescence. Plant Cell Physiol. 49, 142-156. doi: 10.1093/pcp/ pcn006

Zavodszky, E., Seaman, M. N. J., Moreau, K., Jimenez-Sanchez, M., Breusegem, S. Y., Harbour, M. E., et al. (2014). Mutation in VPS35 associated with Parkinson's disease impairs WASH complex association and inhibits autophagy. Nat. Commun. 5, 3828. doi: 10.1038/nco mms 4828

Zimin, A. V., Delcher, A. L., Florea, L., Kelley, D. R., Schatz, M. C., Puiu, D., et al. (2009). A whole-genome assembly of the domestic cow, Bos taurus. Genome Biol. 10:R42. doi: 10.1186/gb-2009-10-4-r42
Conflict of Interest Statement: The authors declare that the research was conducted in the absence of any commercial or financial relationships that could be construed as a potential conflict of interest.

Copyright (๑ 2016 Duchemin, Glantz, de Koning, Paulsson and Fikse. This is an open-access article distributed under the terms of the Creative Commons Attribution License (CC BY). The use, distribution or reproduction in other forums is permitted, provided the original author(s) or licensor are credited and that the original publication in this journal is cited, in accordance with accepted academic practice. No use, distribution or reproduction is permitted which does not comply with these terms. 